\title{
The Effect of Process Parameters on Microstructural and Mechanical Properties of Friction Stir Welded Age-Hardenable Aluminium Alloy
}

\author{
Vuppula Prasanna, P. Ramesh Babu
}

\begin{abstract}
FSW has become the most effective technology in solving problems that have reached the profiled sheets with the continuation of material, particularly in the aerospace industry, with the use of different joining techniques that require high ductility and tensile strength. Current study, FS weldments AA6061-T6 were successfully obtained with varying processing parameters and were mechanically and metallurgically characterized. This paper illustrates macrostructure analysis, influence of tool geometry and process parameters, Fractography analysis microstructure analysis, microhardness of aluminium alloy AA6061-T6.
\end{abstract}

Keywords: AA6061-T6, Friction stir welding, Grain size, Mechanical properties, Microstructural studies, stir zone, Tool rotational speed, Travel speed.

\section{INTRODUCTION}

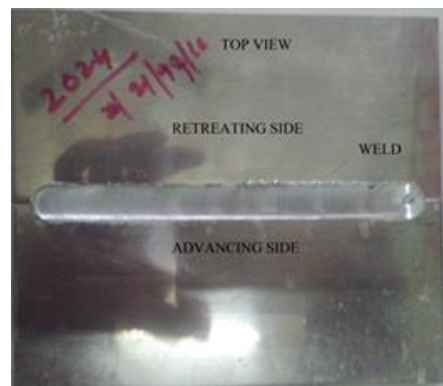

Fig 1 Top and bottom of the joint
Revised Manuscript Received on February 05, 2020.

* Correspondence Author

Vuppula Prasanna,Mechanical*, department, Institute of Aeronautical Engineering,Dundigal,Hyderabad-500043,India

Email: Vuppula.prasanna@yahoo.com

P. Ramesh Babu, Head of Mechanical department, Osmania University Hyderabad, India. Email: prb.mech@gmail.com

(C) The Authors. Published by Blue Eyes Intelligence Engineering and Sciences Publication (BEIESP). This is an open access article under the CC BY-NC-ND license (http://creativecommons.org/licenses/by-nc-nd/4.0/)

\section{A. Visual inspection results}

Visual inspection is displayed on welding samples obtained from a variety of welding Parameters to verify defects like surface irregularities, high flash, and lack of penetration or surface open tunnels.

\section{B. Visual Inspection before welding}

After preparation two plates are clamped in welding fixture which qualities welding.

> Edges of plates before welding should have good finish, with cleaned surface from oil and dirt to get defect free welded joints.

$>$ Securely fix plates without any gap between the welding edges, this gap if it exists effects weld quality and then the welded joint may be has a defect in the welded line.

$>$ Positioning accurately two edges of plates on the same axis of welding tool ( $\mathrm{z}$ axis), otherwise bending occurred due to force applied from tool shoulder and probe on the plate that produce gab dawn the interface of two plates.

\section{Radiography Inspection Results}

According to radiography inspection results (conducted using $100 \mathrm{KVA}$ and $5 \mathrm{~mA}$ source, Exp. time $36 \mathrm{sec}$ ), only two (plates) joints had been accepted from the inspector as shown in Fig 2 (sample 1, 2 and 3, 4) FSW 5 and 6 have internal defect in weld line. The type of defect is evaluated as incomplete fusion (tunnel or worm hole), incomplete cap. Radiography inspection results did not (as expected) reveal any type of porosity or blow holes or any type of hot cracking because no melting and freezing occurs in welding process due to the solid state nature of (FSW) process [1].

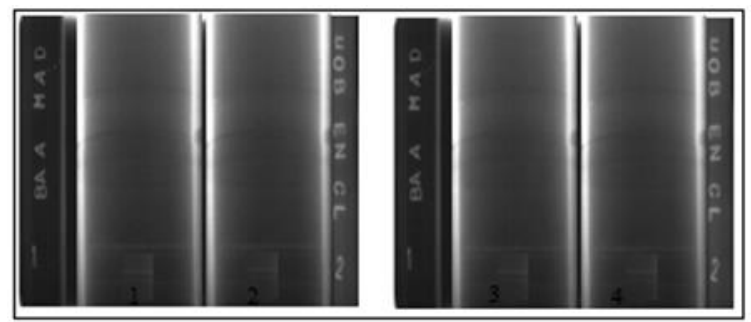

Fig 2 Radiographic inspection film

(a) 1 \&2 Samples 800rpm with $60 \mathrm{~mm} / \mathrm{min}$

(b) 3 \& 4 Samples $1200 \mathrm{rpm}$ with $150 \mathrm{~mm} / \mathrm{min}$ 
The Effect of Process Parameters on Microstructural and Mechanical Properties of Friction Stir Welded Age-Hardenable Aluminium Alloy

\section{METHODOLOGY}

AA6061-T6 belongs to a group of heat treatable 6xxx series which contains Al-Mg-Si as major composition. The required welding sizes of $120 \mathrm{~mm}$ x $100 \mathrm{~mm}$ x 3mm were used. The cast AA6061-T6, Al-Si-Cu or Al-Si-Cu-Mg belongs to aluminium alloys. Copper and magnesium grows at its peak and elevated temperatures when its strength and hardness grows. It has good weldability and corrosion resistance. The sides of the plates will be checked for parallel to the correct clamp in the FSW divisions, which will consolidate the movement for the welding process of movement. The composition and properties of AA6061-T6 are listed in Table 1 and Table 2.

Table 1Mechanical properties of Aluminium of Base metal AA6061-T6

\begin{tabular}{|c|c|c|c|c|c|c|c|}
\hline 6061-T6 & $\mathbf{C u}$ & $\mathbf{M g}$ & $\mathbf{M n}$ & $\mathbf{F e}$ & $\mathbf{C r}$ & $\mathbf{S i}$ & $\mathbf{A l}$ \\
\hline Standard & 0.31 & 0.99 & 0.08 & 0.25 & 0.16 & 0.66 & Balance \\
\hline Observed & 0.30 & 1.00 & 0.06 & 0.19 & 0.13 & 0.67 & Balance \\
\hline
\end{tabular}

Table 2 Chemical Composition of Aluminium Base metal AA6061-T6

\begin{tabular}{|c|c|c|c|c|}
\hline Alloy & $\begin{array}{c}\mathbf{0 . 2 \%} \\
\text { Yield } \\
\text { Strength } \\
\text { (MPa) }\end{array}$ & UTS & $\begin{array}{c}\text { Elongation } \\
\mathbf{( \% )}\end{array}$ & Hardness \\
\hline Standard & 198 & 240 & 26 & 105 \\
\hline Observed & 183 & 236 & 22 & 103 \\
\hline
\end{tabular}

\section{RESULT AND DISCUSSION}

The tool rotation speed is expected to have a momentous impingement on the tensile tests of the joints. Base metal yield strength and tensile strength are $198 \mathrm{MPa}, 240 \mathrm{MPa}$. $1200 \mathrm{rpm}$ with $150 \mathrm{~mm} / \mathrm{min}, 5 \mathrm{KN}$ axial force, $178 \mathrm{MPa}$ tensile strength, $7 \%$ of elongation and $78 \%$ joint efficiency. Rotational speed of $800 \mathrm{rpm}$, the joint is designed to show more tensile strength. To interpret cause of tensile features on joints, macrostructure, microstructure analysis and microhardness are performed and the results are displayed in the following sections [6, 7].

Table 4 Process Parameters on Al alloy AA6061-T6

\begin{tabular}{|c|c|c|c|c|c|c|c|c|c|}
\hline $\begin{array}{l}\text { S. } \\
\text { No }\end{array}$ & $\begin{array}{c}\text { Rotational } \\
\text { Speed } \\
\text { (rpm) }\end{array}$ & $\begin{array}{c}\text { Travel } \\
\text { speed } \\
(\mathrm{mm} / \mathbf{m i n})\end{array}$ & $\begin{array}{l}\text { Width } \\
\text { (mm) }\end{array}$ & $\begin{array}{c}\text { Thickness } \\
\text { (mm) }\end{array}$ & $\begin{array}{c}\text { Sp. Gauge } \\
\text { length } \\
(\mathrm{mm})\end{array}$ & $\begin{array}{c}\text { 0.2 Yield } \\
\text { Strength } \\
\text { (MPa) }\end{array}$ & $\begin{array}{c}\text { Ultimate Tensile } \\
\text { Strength } \\
\text { (MPa) }\end{array}$ & $\begin{array}{c}\text { Elongation } \\
(\%)\end{array}$ & 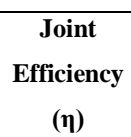 \\
\hline 1 & 800 & 150 & 5 & 3 & 25 & 156 & 215 & 8.0 & 89.5 \\
\hline 2 & 1200 & 150 & 5 & 3 & 25 & 150 & 210 & 7.0 & 87.5 \\
\hline 3 & 800 & 60 & 5 & 3 & 25 & 136 & 178 & 7.0 & 74.1 \\
\hline 4 & 1200 & 60 & 5 & 3 & 25 & 124 & 173 & 6.0 & 72.0 \\
\hline
\end{tabular}

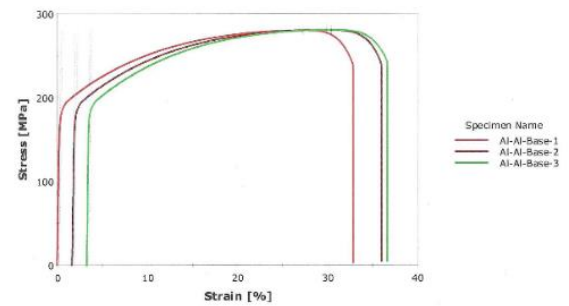

Fig 4 Graph for stress Vs strain aluminium sample base metal 


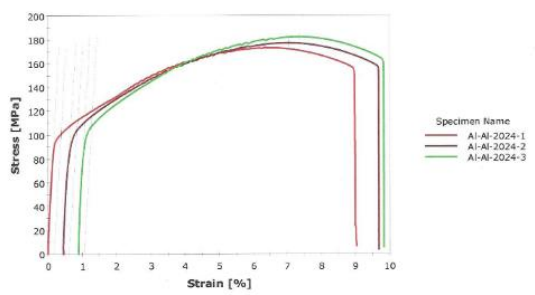

Fig 5 Graph between Stress Vs Strain for rotational speed $800 \mathrm{rpm}$ and travel speed of $60 \mathrm{~mm} / \mathrm{min}$

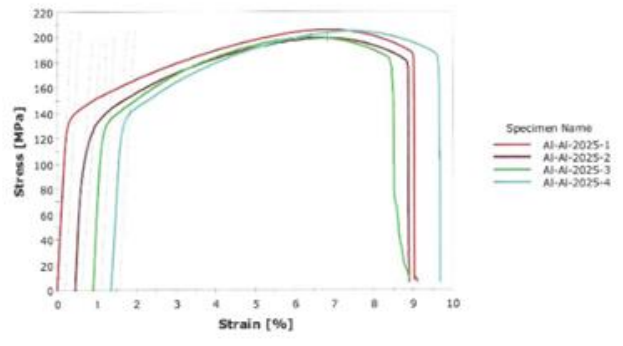

Fig 6 Graph between Stress Vs Strain for rotational speed $1200 \mathrm{rpm}$ and travel speed of $150 \mathrm{~mm} / \mathrm{min}$

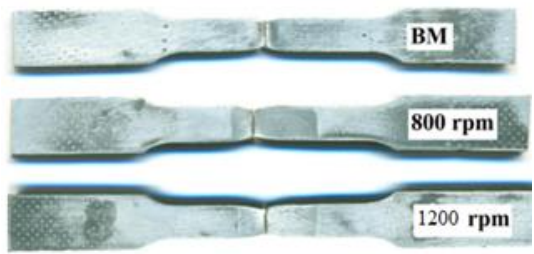

Fig 7 Fracture location of the tensile specimens for the BM and joints welded at constant rotation speed of 800 rpm and 1200rpm.

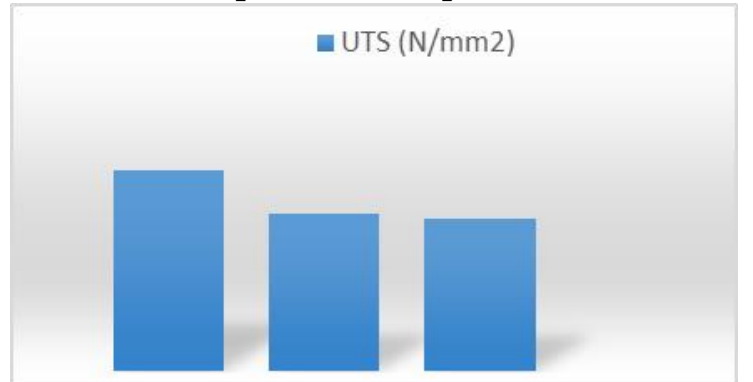

Fig 8 Graph between Stress Vs Rotational speed for Base Metal, Sample 1 and Sample 2

Fig 7 tensile strength of aluminium alloy AA6061-T6 reveals the influence of rotation speed in the joint. At low rotation speed $(800 \mathrm{rpm})$, the tensile strength is high. At 800 rpm, it increases the tensile strength and reaches maximum. If the rotation speed is increased $1200 \mathrm{rpm}$, the tensile strength of the joint is reduced [4]. Higher tool rotation speed (1200 rpm) causes higher grain size as a result of high heat input per unit length and slow cooling rate in FSW zone, leading to lower tensile characteristics of the joints. High rotation speed releases stirred materials to the upper surface, resulting in the micro-voids in the SZ causing the lower tensile characteristics of the joints. If the low rotation speed results low thermal input for $800 \mathrm{rpm}$ per unit length, the result does not have sufficient plastics and is one of the causes of high tensile characteristics of the joints. At a rotating speed of $1200 \mathrm{rpm}$, displays minimal tensile strength and can cause optimum thermal production.
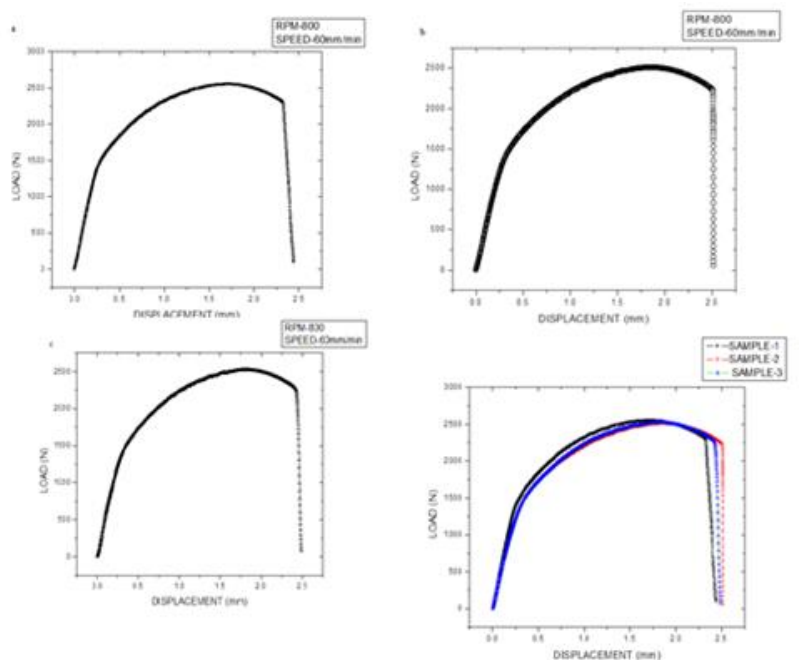

Fig 9 Load Vs Displacement a) Sample 1 b) Sample 2 c) Sample 3 with rotational speed 800rpm and Travel speed of $60 \mathrm{~mm} / \mathrm{min}$.
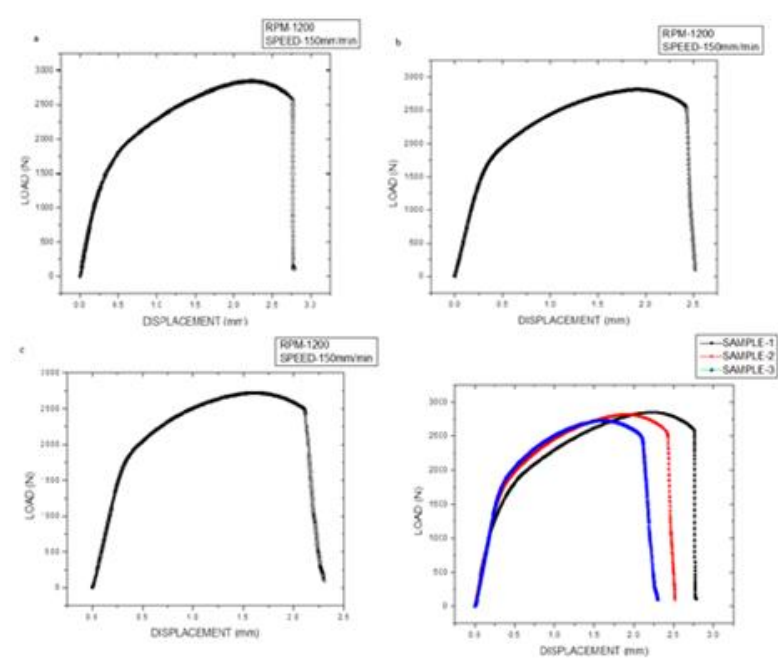

Fig 10 Load Vs Displacement a) Sample 1 b) Sample 2 c) Sample 3 with rotational speed 1200rpm and Travel speed of $150 \mathrm{~mm} / \mathrm{min}$.

\section{Microhardness}

Micro hardness is measured in the mid area across the width of the plate shown in Fig 11. Parent metal has hardness of $105 \mathrm{Hv}$, less than the nugget zone, more than TMAZ and parent metal. Two main reasons for better hardness: (i) Nugget zone grain size is better than parent metal, grain refining has a vital role in maximum strength. (ii) Intermetallic compounds are also reason for hardness improvement. The difference in hardness between the heat affected zone and the stir zone is attributed to grain refining in the stir zone. The highest hardness in the joint generated with the rotational speed of the $800 \mathrm{rpm}$ in the TMAZ. At $1200 \mathrm{rpm}$ the maximum value of $117 \mathrm{Hv}$ in the stir zone commonly associated with the rotation of the joint, can cause the best tensile properties of the joint. 


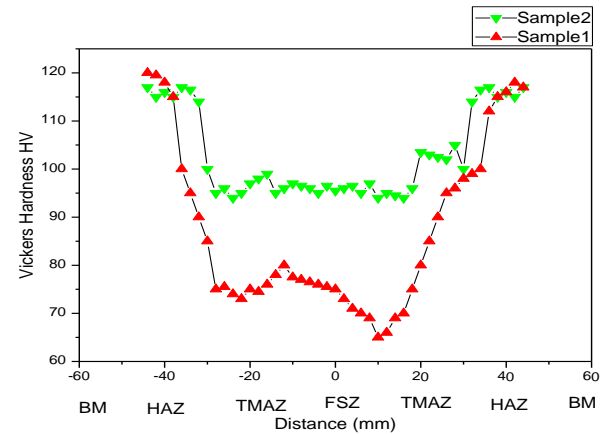

Fig 11 Vickers hardness graph for sample 1 and sample 2

\section{Microstructure}

The microstructure along the cross section of the base metal AA6061-T6 reveals coarse second phase particles and large recrystallized grains. Grains are elongated along the rolling direction. Fig 12 (a, b) shows the optical micrograph taken at the surface of the base plate. The optical microstructures taken along the cross section in the transverse direction of FS welded joints of al alloy AA6061-T6 are observed with three different distinctive zones viz. WN, TMAZ, and HAZ, and these three zones are observed in the FS weld.
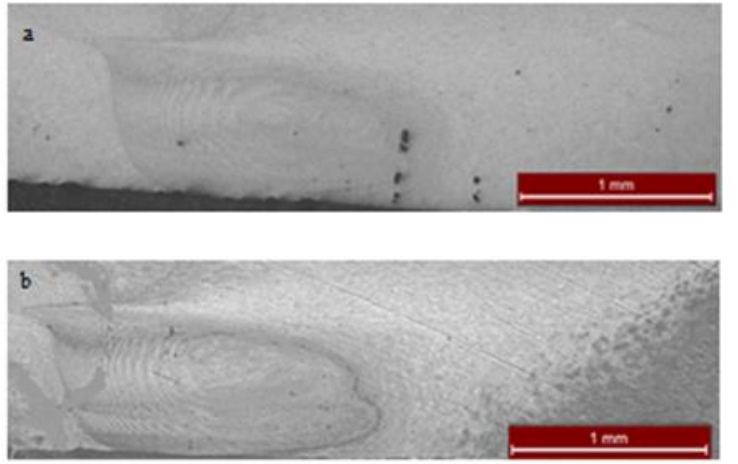

Fig 12 (i) (a), (b) Macrostructure of cross section Aluminium AA6061-T6 alloy

The optical micrographs taken in the areas of stir zone for the joints are displayed in the fig12 (a, b). Above microstructures shows, significant difference in average diameter of grains in stir zone and coarse grains in the base metal are converted to fine grains in the stir zone. Hence, average grain diameter (AGD) on weldments was done by using ASTM Grain size measurement. At 1200rpm 5-8 $\mu \mathrm{m}$ grains are observed due to high tensile characteristics in the joint. Optical micrographs were carried across different areas throughout the weld, but for comparison purposes, the SZ-TMAZ interface areas micrographs were shown in fig12 (a, b). There is an appreciable difference in the TMAZ grain size. Grains in nugget area are better than TMAZ. Which have minimum grain diameter shown in fig12 (b). However, at $800 \mathrm{rpm}$ grains are larger and at $1200 \mathrm{rpm}$ grains are small. Microstructures shows that the metal is pulled from advancing side during stirring action of the tool, therefore it leads to elongation of grains in TMAZ.

\section{X-ray Diffraction}

$\mathrm{XRD}$ is most direct and accurate analytical method of determining the total amounts of existence and elements in a specimen. According to the elemental data from the XRD analysis, the alloy is slightly more than Si and Mg. The high amount of AA6061-T6 allocated from XRD analysis is high corrosion resistance and good efficiency. The XRD only refers to alloy around micro constituents. X-ray diffraction is a non-destroying analytical technique versatile, and with the help of obtain information for recognition and size of different crystalline compounds known as "phase" compounds in the material. X-ray diffraction of the structure is based on the crystallographic planes, the alloy Mg2Si and $\mathrm{Al} 2 \mathrm{O} 3$ were analyze and described. Determination of structural units are the dependence of diffracted radiation and $2 \theta$ deflection angle. Composition phase has been diagnosed by qualitative analysis by X-ray diffraction, X-ray diffraction conducted by the Panalistic X'Pert PRO MPD.

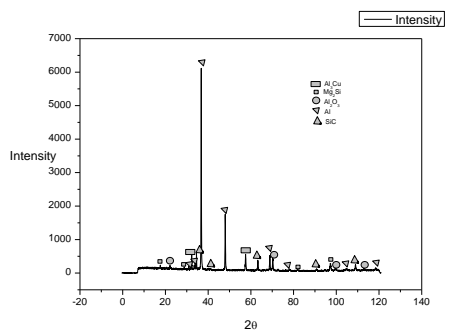

Fig 13 XRD pattern obtained from the Aluminium alloy 6061-T6

\section{SEM with EDAX}

The results of EDS analysis of the base metal AA6061-T6 aluminium alloy is presented in Fig 19 (a, b, c). Images of the base metal shown in Fig 19 (a) and (b) which explore the presence of particles in varying size. The EDS analysis was carried out at the base metal surface (at Area 1 in Fig 19 (a)) particles and their results are plotted in Fig 19 (a), (b) and (c) respectively. The results indicate that the particles are enriched with the metal $\mathrm{Al}$ and therefore, they are $\mathrm{Al} 2 \mathrm{O} 3$ (second phase particles) and Mg2Si (intermetallic particle) as reported by other authors [2].The most commonly found particles in AA6061-T6 are Mg2Si, Al2O3 and SiC [3]. These particles are also responsible for its tensile strength and ductility [4].

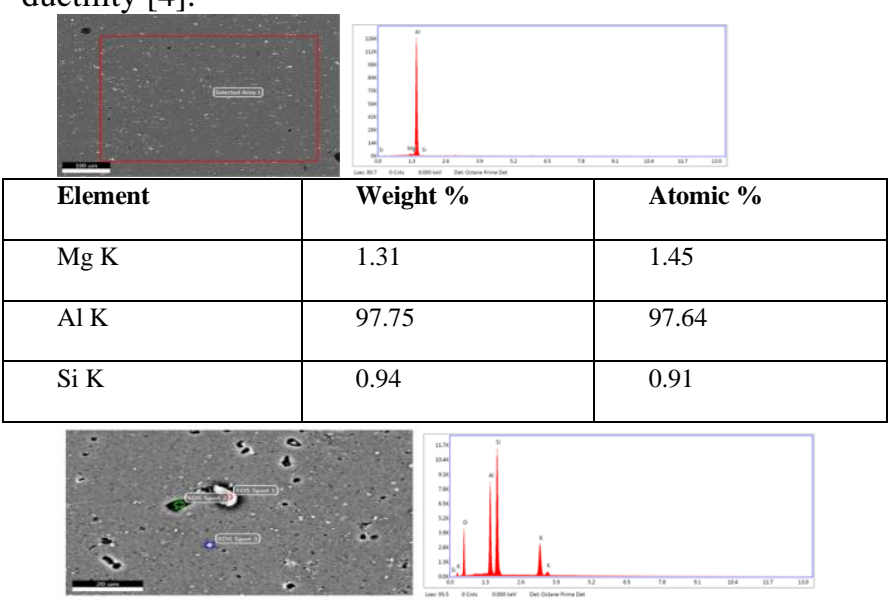

EDS Spot 1 


\begin{tabular}{|c|c|c|}
\hline Element & Weight \% & Atomic \% \\
\hline $\mathrm{Al} \mathrm{K}$ & 18.67 & 15.57 \\
\hline O K & 36.75 & 51.68 \\
\hline Si K & 31.50 & 25.23 \\
\hline K K & 13.08 & 7.52 \\
\hline
\end{tabular}

EDS Spot 2

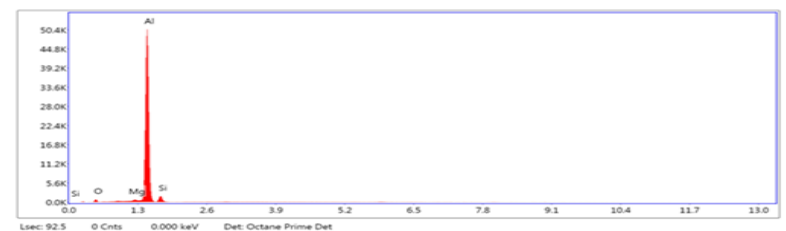

\begin{tabular}{|c|c|c|}
\hline Element & Weight \% & Atomic \% \\
\hline O K & 5.05 & 8.24 \\
\hline Mg K & 1.22 & 1.31 \\
\hline Al K & 85.22 & 82.52 \\
\hline Si K & 8.51 & 7.92 \\
\hline
\end{tabular}

EDS Spot 3

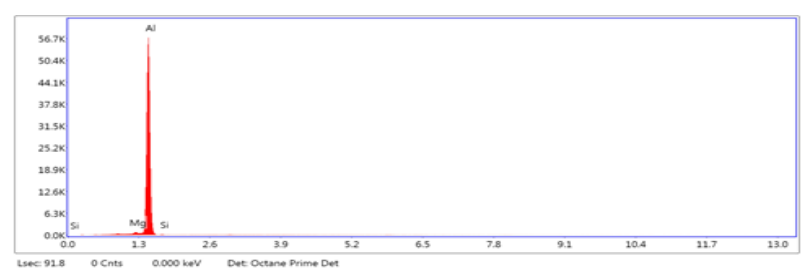

\begin{tabular}{|c|c|c|}
\hline Element & Weight \% & Atomic \% \\
\hline $\mathrm{Mg} \mathrm{K}$ & 1.28 & 1.42 \\
\hline $\mathrm{Al} \mathrm{K}$ & 97.83 & 97.72 \\
\hline $\mathrm{Si} \mathrm{K}$ & 0.89 & 0.86 \\
\hline
\end{tabular}

Fig 19 Results of EDS analysis of the base metal 6061-T6

\section{(a) SEM image showing the presence of particles}

\section{(b) Results of EDS analysis}

\section{IV.CONCLUSION}

Weldments generated at $60 \mathrm{~mm} / \mathrm{min}, 150 \mathrm{~mm}$ / min welding speed and 800 and $1200 \mathrm{rpm}$ at different rotating speeds are sound. Void defects occur at a rotational speed of 800rpm at the interface of parent metal and TMAZ. During FSW, Increasing the temperature and thermal heat input of the weldments cause less grain structure and large secondary phase particles at nugget zone. At low rotational speeds, the defective joints have high hardness and UTS with low elongation. A partial cleavage type with dimples and cleavage facets are formed in the joints. In addition, joints having high rotation speed explains high elastic fracture other than joints having low rotation speed.

\section{ACKNOWLEDGMENT}

I thank head of the Metallurgy department, DMRL, Hyd for giving permission to use the equipment's regarding this project.

\section{REFERENCES}

1. Adamowski J and Szkodo M (2007), "Friction Stir Welds (FSW) of Aluminum Alloy AW6082-T6", Journal of Achievements in Materials and Manufacturing Engineering, Vol. 20.

2. P. Venkateswaran, Zhi-Hui Xu, Xiaodong Li, A. P. Reynolds. Determination of mechanical properties of $\mathrm{Al}-\mathrm{Mg}$ alloys dissimilar friction stir welded interface by indentation methods. J. Mater. Sci.2009; 44(15): 4140-7.

3. Mondolfo, L. F. (1976), Aluminium alloys: Structure and properties, Butterworths \& Co Ltd, Massachusetts, 717-857.

4. Vuppula Prasanna, Dr. A. Seshu Kumar, and Dr. P. Ramesh Babu, "Experimental Studies od Dissimilar Metals Welded Joint by F.S.W", Elsevier Materials Today: Proceedings 18 (2019) 3276-3285.

5. Butterworth Heinemann (2004), 'Smithells Metals Reference Book', Oxford.

6. W. M. Thomas, E. D. Nicholas, J. C. Needham, M. G. Nurch, P Temple-Smith, and C. Dawes, Patents on Friction Stir Butt Welding, International: PCT/GB92/02203; British: 9125978.8; USA: 5460317., 1991-1995.

7. Staley, J.T (1979), Microstructure and toughness of high strength alloys, Aluminium, 55, 277-281.

8. Hatch, J. E (1984) Aluminium: Properties and Physical Metallurgy, Materials Park, OH, ASM International, 140, 64-69.

\section{AUTHORS PROFILE}

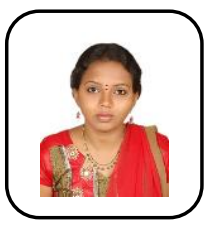

Vuppula Prasanna, received her Bachelor's degree in Mechanical Engineering from Sree Visveswarayya Institute of Science and Technology,

Mahbubnagar in 2006,the Master's degree in Advanced Manufacturing Systems from Jawaharlal Nehru Institute of Technological University, Hyderabad in 2010 and Perusing Ph.D. on Friction Stir Welds from Osmania University, Hyderabad. She is Assistant Professor with Department of Mechanical Engineering in Various Engineering Colleges like Vignana Bharathi Institute of Technology, St. Mary's Engineering College, TKR Engineering College and GuruNanak Institutions Hyderabad, Present working in Institute of Aeronautical Engineering, Dhundigal, Hyderabad. Her research interests on Welding Science and Engineering under Specializations on Production Engineering. At present she is engaged with Experimental work with various dissimilar metals, tests performed on those metals. 